\title{
The novel focal adhesion gene kindlin-2 promotes the invasion of gastric cancer cells mediated by tumor-associated macrophages
}

\author{
ZHANLONG SHEN $^{1,2^{*}}$, YINGJIANG YE ${ }^{1 *}$, TUULI KAUTTU ${ }^{2}$, HANNA SEPPÄNEN $^{2}$, \\ SANNA VAINIONPÄ̈̈ ${ }^{2}$, SHAN WANG $^{1}$, HARRI MUSTONEN ${ }^{2 * *}$ and PAULI PUOLAKKAINEN ${ }^{2 * *}$ \\ ${ }^{1}$ Department of Gastroenterological Surgery, Peking University People's Hospital, Beijing 100044, P.R. China; \\ ${ }^{2}$ Department of Surgery, Helsinki University Central Hospital, and University of Helsinki, Helsinki 00290, Finland
}

Received August 28,2012; Accepted September 20, 2012

DOI: $10.3892 / o r .2012 .2137$

\begin{abstract}
Kindlin-2 is a novel focal adhesion gene mediating the cell-extracellular matrix (ECM) adhesion. Tumor-associated macrophages (TAMs) play an important role in linking chronic inflammation to cancer progression. Both kindlin-2 and TAMs have been found to promote the invasion of gastric cancer cells in our previous studies. However, the correlation between kindlin-2 and TAMs remains unclear. Real-time RT-PCR was used to investigate kindlin-2 expression in the AGS, NCI and Hs-746T gastric cancer cell lines co-cultured with TAMs under normal or hypoxic conditions. IL8, IL10, IL11, IL17b, IL18, IL22 and IL24 expressions were measured by real-time RT-PCR in the gastric cancer lines with varying levels of kindlin-2 expression, as well as after downregulation of kindlin-2 mRNA expression by the siRNA method. We found that kindlin-2 was upregulated in all three gastric cancer cell lines when co-cultured with TAMs under normal conditions. Under hypoxic conditions, the induction of kindlin-2 expression induced by macrophages was significantly downregulated in the Hs-746T cell line. IL8, IL11, IL17b, IL22 and IL24 expression was significantly higher in gastric cell lines with high kindlin-2 expression. Downregulation of kindlin-2 mRNA decreased IL10, IL11, IL17b, IL22 and IL24 expression but IL8 and IL18 expression was upregulated. Therefore, the novel focal adhesion gene kindlin- 2 may play an important role in promoting the invasion of gastric cancer cells mediated by TAMs through regulating interleukin expression.
\end{abstract}

Correspondence to: Dr Pauli Puolakkainen, Department of Surgery, Helsinki University Central Hospital, and University of Helsinki, Helsinki 00290, Finland

E-mail: pauli.puolakkainen@hus.fi

Dr Shan Wang, Department of Gastroenterological Surgery, Peking University People's Hospital, Beijing 100044, P.R. China

E-mail: wangshan@yahoo.com.cn

*Contributed equally

***oint senior authorship

Key words: kindlin-2, tumor-associated macrophages, interleukin, gastric cancer, invasion

\section{Introduction}

Kindlin-2 is a member of the focal adhesion protein family recruited to integrin-containing adhesion sites (1-3). Kindlin-2 is localized to cell-extracellular matrix (ECM) adhesion sites, and has been shown to interact directly with the cytoplasmic tail of $\beta 1$ and $\beta 3$-integrin. Kindlin- 2 overexpression has been shown to induce a modest activation of the $\alpha \mathrm{IIb} \beta 3$-integrin (4). Integrin-mediated cell adhesion triggers intracellular signaling pathways that control migration, proliferation, survival, and differentiation of cells including cancer cells (5). Although kindlin-2 has been confirmed as an essential element of bidirectional integrin signaling (6), little is known about the expression of kindlin- 2 in association with human cancer. Recent studies have shown that kindlin-2 was differentially expressed in prostate, uterine leiomyosarcoma and malignant mesothelioma (7-9). In our previous study, we found that kindlin-2 was upregulated at both the RNA and protein levels in gastric cancer tissues. Moreover, kindlin-2 expression had a significant positive correlation with tumor stromal invasion, lymph node metastasis and TNM stage. Patients with high kindlin-2 expression had significantly poorer overall survival and progression free survival. Thus, kindlin- 2 might play an important role in the invasion and metastasis of gastric cancer.

Chronic inflammation has been linked to the development of cancer (10). Individuals with ulcerative colitis, which is a chronic inflammatory disease of the colon, have a 10 -fold increase in likelihood of developing colorectal carcinoma. Similarly, inflammatory conditions of the liver, such as chronic hepatitis and cirrhosis, are well established risk factors for the development of hepatocellular carcinoma (11). Tumorassociated macrophages (TAMs) have been highlighted to play an important role in malignant progression of neoplasm $(12,13)$. For many tumors, high numbers of TAMs correlate with lymph node involvement or the formation of distant metastases $(14,15)$. Clinical studies have shown a correlation between the high number of TAMs in the areas of tumors and increased microvessel density and poor prognosis (16-18). Our previous study showed that the TAMs play a role in regulating invasion and metastasis in gastric cancer cells. However, the molecular mechanism underlying the link between the inflammation mediated by macrophages and gastric cancer remains unclear. 
Although both kindlin-2 and macrophages have been shown to be correlated with the invasion and metastasis of gastric cancer in our previous studies, we do not know whether the kindlin-2 gene is involved in the inflammatory process of promoting invasion of gastric cancer cells.

IL8, IL10, IL11 have been found to be expressed in gastric cancer (19-21), but the expressions of IL17b, IL22 and IL24 in gastric cancer remain undefined. Moreover, so far there have been no reports on the relationship between inflammatory factors and kindlin-2 expression. In our study, we found that the kindlin-2 gene was not only significantly elevated when the gastric cancer cells were co-cultured with TAMs, but this elevation could also be induced by hypoxia. Furthermore, the interleukin expressions, with the exception of IL11, were significantly changed following kindlin-2 downregulation.

\section{Materials and methods}

Isolation of monocytes and macrophages. Mononuclear cells were isolated from the blood of healthy subjects with density gradient centrifugation (Ficol-Paque; Amersham, Uppsala, Sweden). There were three layers of liquid after density gradient centrifugation, mononuclear cells were in the second cloudy layer, and it was transferred to a clean tube and centrifuged. The cells were washed with PBS+10\% ACD (acid citrate dextrose solution) solution two times. The cells were counted and $1.4 \times 10^{6}$ cells were placed on Matrigel (BD Biosciences, San Jose, CA, USA) covered coverslip (Nalge Nunc International Corp., Naperville, IL, USA). The isolated cells were grown in serum-free medium designed for macrophages (Macrophage serum free medium; Gibco, Paislay, UK) with granulocyte-macrophage colony-stimulating factor (GM-CSF, 10 ng/ml; ImmunoTools, Oldenburg, Germany), antibiotics and $5 \% \mathrm{CO}_{2}$ at $37^{\circ} \mathrm{C}$. Monocytes adhered to the Matrigel overnight and differentiated to macrophages due to GM-CSF; other non-adherent mononuclear cells were removed from the medium the following day. Monocytes were fully differentiated into macrophages after six days and then used for experiments. When co-cultured with cancer cells, macrophages developed into TAMs with special surface marker, $\mathrm{CD}_{14}{ }^{+}(22)$. After co-culturing with gastric cancer cells, the portion of $\mathrm{CD}_{14}{ }^{+}$positive macrophages reached $>80 \%$ measured with flow cytometry.

Gastric cancer cell culture. The AGS cell line (CRL-1739) derived from fragments of a tumor resected from gastric cancer patients, was purchased from ATCC (American Type Culture Collection). The cells were cultured in Ham's F12K medium with $2 \mathrm{mM} \mathrm{L}$-glutamine adjusted to contain $1.5 \mathrm{~g} / \mathrm{l}$ sodium bicarbonate, $10 \%$ fetal bovine serum (FBS) and antibiotics $(100 \mu \mathrm{g} / \mathrm{ml}$ penicillin and $100 \mathrm{U} / \mathrm{ml}$ streptomycin).

The Hs 746T (HTB-135) cell line was purchased from ATCC. It was derived from a metastatic tumor of the left leg of a gastric cancer patient. Cells were cultured in Dulbecco's modified Eagle's medium (DMEM) with $4 \mathrm{mM} \mathrm{L-glutamine}$ adjusted to contain $1.5 \mathrm{~g} / \mathrm{l}$ bicarbonate, $4.5 \mathrm{~g} / \mathrm{l}$ glucose, $10 \%$ FBS and antibiotics $(100 \mu \mathrm{g} / \mathrm{ml}$ penicillin and $100 \mathrm{U} / \mathrm{ml}$ streptomycin).

The NCI-N87 (CRL-5822) cell line was derived from the metastatic liver tumor of a gastric cancer patient. It was purchased from ATCC. Cells were cultured in RPMI-1640 medium, supplemented with 10\% FBS and antibiotics $(100 \mu \mathrm{g} / \mathrm{ml}$ penicillin and $100 \mathrm{U} / \mathrm{ml}$ streptomycin).

All gastric cancer cell lines were maintained at $37^{\circ} \mathrm{C}$ in a humidified atmosphere with $5 \% \mathrm{CO}_{2}$.

Cell sorting by magnetic separation. Cell sorting was performed after gastric cancer cells were cultured with macrophages for $24 \mathrm{~h}$. Cell sorting was processed by MACS separator (MACS Miltenyi Biotec, Germany), which is based on magnetic separation. After Matrigel contained cells were dissolved and centrifuged, $80 \mu \mathrm{l}$ of Buffer (degassed PBS with 0.5\% BSA and $2 \mathrm{mM}$ EDTA) and $20 \mu \mathrm{l}$ CD14 MicroBeads (MACS Miltenyi Biotec) were added to the deposit and incubated for $20 \mathrm{~min}$ at $4^{\circ} \mathrm{C}$. Then the cells were washed by Buffer and centrifuged. Cells resuspended with Buffer were transferred to the prepared LS column (MACS Miltenyi Biotec). Total effluents which contained gastric cancer cells and CD14 negative macrophages were collected and centrifuged. The cell pellets were resuspended in buffer and CD11b MicroBeads, and the above mentioned separating protocol was repeated.

Invasion and migration assay (3D dynamic migration imaging system). Cells were grown on Matrigel covered coverslip wells with serum-free medium designed for macrophages. Gastric cancer cells were grown either alone or with differentiated macrophages on Matrigel and either in normal $\left(5 \% \mathrm{CO}_{2}\right.$ in air) or hypoxic conditions $\left(\mathrm{CO}_{2} 5 \%, \mathrm{O}_{2} 2 \%, \mathrm{~N}_{2} 94 \%\right)$. Gastric cancer cells $\left(6 \times 10^{4}\right)$ were seeded in each well of the coverslip. Gastric cancer cells were stained with fluorescent dye (CellTracker green CMFDA; Invitrogen, Eugene, OR, USA) before imaging. During the invasion phase the cancer cells invaded in Matrigel were imaged by 3D dynamic migration imaging system (Olympus Ax70 Research System Microscope, Japan; 12Bit Cooled Imaging Sensicam camera; PCD Imaging, Kelheim, Germany). The average migration speed was calculated from the cells which could be tracked at least for $6 \mathrm{~h}$ in one z-plane (ImagePro Plus; Media Cybernetics, Inc., Bethesda, MD, USA).

Real-time RT-PCR. Total-RNA was isolated from the sorted cells by membrane binding (RNeasy Mini kit, 74104; Qiagen, Hilden, Germany). RNA was reverse transcribed to single stranded cDNA by the reverse transcriptase method (High Capacity cDNA Reverse Transcription kit, 4368814; Applied Biosystems, Bardburg, NJ, USA). The target gene expression was measured by the real-time RT-PCR method (TaqMan Gene Expression Assay; Applied Biosystems). GAPDH was used as endogenic control (TaqMan Endogenous Controls; Applied Biosystems). The PCR reactions were run in ABI PRISM 7000 sequence detection system. $2^{-\Delta \Delta C T}$ referred to the fold of the mRNA expression of one sample compared to the calibration sample. $2^{-\Delta \mathrm{Ct}}$ was defined as the fold of mRNA expression of the target gene compared to GAPDH expression in the same sample.

Western blotting. Gastric cancer cells were lysed in radioimmunoprecipitation assay (RIPA) buffer $(50 \mathrm{mmol} / 1 \mathrm{Tris}-\mathrm{Cl}$, $150 \mathrm{mmol} / 1 \mathrm{NaCl}, 1 \% \mathrm{NP}-40,0.5 \%$ sodium deoxycholate, and $0.1 \%$ sodium dodecyl sulfate, $\mathrm{pH} 7.5$ ) containing $1 \mathrm{mmol} / 1$ phenylmethylsulfonyl fluoride for $30 \mathrm{~min}$ on ice. The samples 


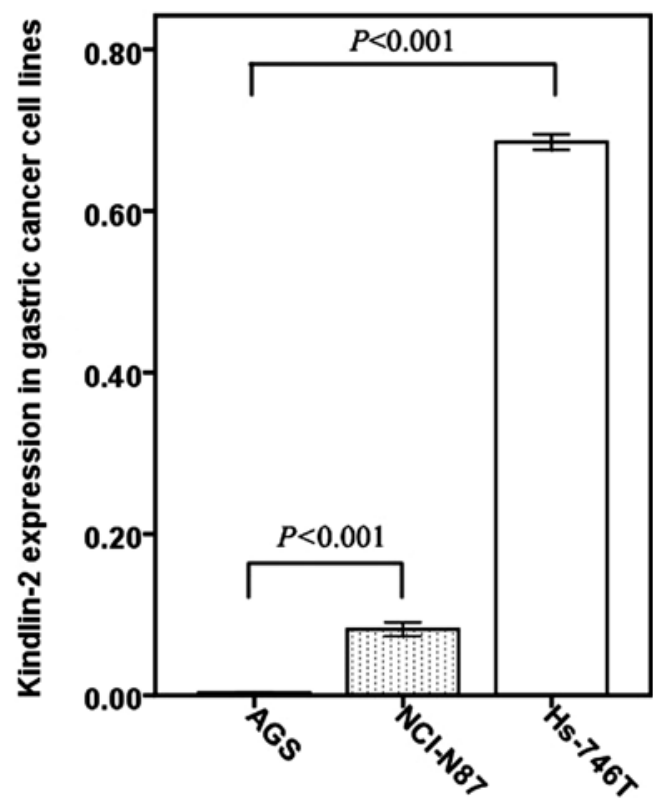

Figure 1. Kindlin-2 expression in gastric cancer cell lines.

were centrifuged and the protein concentrations for each sample were determined using the Bio-Rad Protein Assay (Bio-Rad Laboratories, Hercules, CA, USA). The protein samples $(20 \mathrm{~g})$ were separated by $10 \%$ sodium dodecyl sulfate (SDS)-polyacrylamide gel electrophoresis, and then electrotransferred to a nitrocellulose membrane. After blocking with $5 \%$ nonfat dry milk in Tween-Tris-buffered saline solution [0.1\% Tween-20 in $100 \mathrm{mmol} / 1$ Tris- $\mathrm{Cl}$ (pH 7.5), 0.9\% NaCl], the membranes were incubated with antibody to kindlin-2 (ab74030; Abcam, USA) at a dilution of 1:600 at $4^{\circ} \mathrm{C}$ overnight. After washing, the blots were incubated with horseradish peroxidase conjugated secondary antibodies at a dilution of 1:10,000 for kindlin-2 for $1 \mathrm{~h}$. The blot was washed and developed using chemiluminescence (Santa Cruz Biotechnology, Inc., Santa Cruz, CA, USA). For control, we also blotted the membranes with primary antibodies against $\beta$-actin (sc-47778; Santa Cruz Biotechnology, Inc.) and densitometric data of kindlin-2 were normalized to those of $\beta$-actin levels.

siRNA transfection. In a 6 -well tissue culture plate, $2 \times 10^{5}$ Hs-746T cells/well were seeded in $2 \mathrm{ml}$ antibiotic-free DMEM medium supplemented with FBS. The cells were incubated at $37^{\circ} \mathrm{C}$ until the cells were $60-80 \%$ confluent. siRNA transfection kit (sc-45064; Santa Cruz Biotechnology, Inc.) was used to downregulate the expression. The cells were divided into three groups: blank control group, negative control group, and kindlin-2 siRNA group. Six microliters of kindlin-2 siRNA duplex (sc-10676) or control siRNA duplex (sc-37007) were added into $100 \mu \mathrm{l}$ siRNA transfection medium (sc-36868) (all were from Santa Cruz Biotechnology, Inc.) as the kindlin-2 siRNA group or negative control group, respectively. In the blank control group, $6 \mu$ l transfection medium was used instead of duplex. For each transfection group, $6 \mu 1$ siRNA transfection (sc-29528; Santa Cruz Biotechnology, Inc.) reagent was added into $100 \mu \mathrm{l}$ siRNA transfection medium. Thereafter, they were mixed gently and incubated for $45 \mathrm{~min}$ at room
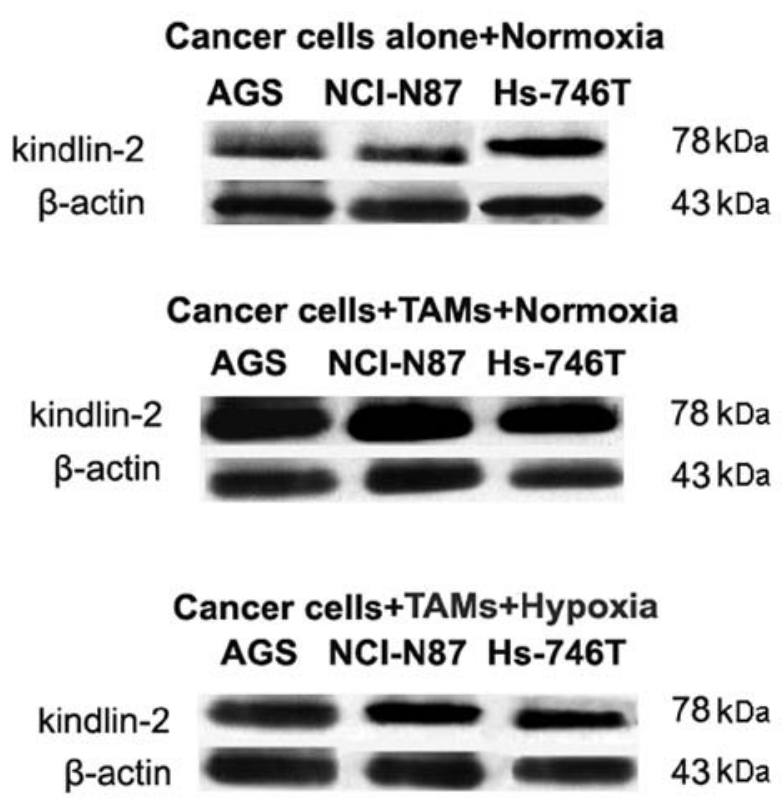

Figure 2. Effect of macrophages on the kindlin-2 expression under normal and hypoxic conditions (western blotting results). Kindlin-2 was upregulated in the three gastric cancer cell lines when co-cultured with macrophages under normal conditions. The elevation of kindlin-2 expression was the highest in the AGS cell line and the lowest in the Hs-746T cell line. Under hypoxic conditions, the induction of kindlin- 2 expression by macrophages was significantly downregulated in all three cell lines, but in Hs-746T the downregulation was decreased even more than in the two other cell lines.

temperature. The cells were washed once with $2 \mathrm{ml}$ siRNA transfection medium. Then the mixed solution was overlaid the washed cells and incubated for $7 \mathrm{~h}$ in a $\mathrm{CO}_{2}$ incubator. Subsequently, $1 \mathrm{ml}$ DMEM medium containing 2-fold the normal serum and antibiotics concentration was added without removing the transfection mixture. The cells were incubated for an additional $24 \mathrm{~h}$. The medium was replaced with normal DMEM medium the next day. The RNA of cells was extracted after $24 \mathrm{~h}$.

Statistical analysis. Statistical package for social science (SPSS) version 17.0 was used. Data are expressed as the means \pm SEM. One way ANOVA was used to compare the cell movement speed data and mRNA expression data between different groups. $\mathrm{P}<0.05$ was considered to indicate statistically significant differences.

\section{Results}

Kindlin-2 relative expression in gastric cancer cell lines. Kindlin-2 mRNA relative expression (kindlin-2/GAPDH) was higher in metastatic gastric cancer cell lines than in the nonmetastatic gastric cancer cell line. Kindlin-2 mRNA expression was the highest in the Hs-746T cell line $(658.4 \pm 4.8)$, and the lowest in the AGS cell line (2.3 \pm 0.6$)$. Kindlin- 2 mRNA relative expression in the NCI-N87 cell line was $81.8 \pm 4.3(\mathrm{~N}=6)$ (Fig. 1). Kindlin-2 expression in protein level was verified by western blot analysis (Fig. 2).

Effect of TAMs on kindlin-2 expression in gastric cancer cell lines under normal or hypoxic conditions. Both kindlin-2 
Table I. Effect of macrophages on the kindlin-2 expression in gastric cancer cell lines under normal or hypoxic conditions.

Kindlin-2 mRNA relative expression $\left(2^{-\Delta \Delta C t}\right)$

Cultured with/without macrophages under normal conditions
Cultured with macrophages under

hypoxic/normal conditions $\left(\times 10^{-2}\right)$
P-value

\begin{tabular}{|c|c|c|c|c|}
\hline AGS & $4789.6 \pm 149.3$ & & $7.1 \pm 0.2$ & \\
\hline NCI-N87 & $455.1 \pm 9.5$ & $\mathrm{P}<0.001^{\mathrm{a}}$ & $5.8 \pm 0.0$ & 0.159 \\
\hline Hs-746T & $157.7 \pm 6.6$ & $\mathrm{P}<0.001^{\mathrm{a}}$ & $0.5 \pm 0.2$ & $0.036^{\mathrm{a}}$ \\
\hline
\end{tabular}

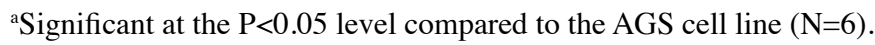

Table II. Correlation between kindlin-2 and interleukin expression.

\begin{tabular}{lcc}
\hline & Pearson's correlation co-efficient (r) & P-value \\
\hline IL8 & 0.988 & $<0.001^{\mathrm{a}}$ \\
IL10 & -0.308 & 0.553 \\
IL11 & 0.996 & $<0.001^{\mathrm{a}}$ \\
IL17b & 0.919 & 0.010 \\
IL18 & -0.712 & 0.113 \\
IL22 & 0.990 & $<0.001^{\mathrm{a}}$ \\
IL24 & 0.993 & $<0.001^{\mathrm{a}}$ \\
\hline
\end{tabular}

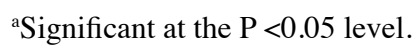

mRNA and protein were upregulated in all three gastric cancer cell lines, when co-cultured with macrophages under normal conditions. The elevation of kindlin-2 expression was significantly higher in the non-metastatic cell line AGS than in the two other cell lines.

Under hypoxic conditions, the induction of kindlin-2 expression by macrophages was significantly downregulated in all cell lines; AGS $(\mathrm{P}<0.001)$, NCI-N87 $(\mathrm{P}<0.001)$ and Hs-746T $(\mathrm{P}=0.013)(\mathrm{N}=6)$ (Table I). The effect of macrophage and hypoxia on kindlin-2 expression in protein level were in accordance with mRNA results (Fig. 2).

Expression of interleukin in gastric cancer cell lines with variable kindlin-2 expression. IL8, IL11, IL17b, IL24 expressions were the lowest in the AGS cell line which also had the lowest kindlin-2 expression, and the highest in the Hs-746T cell line, which had the highest kindlin-2 expression. There was a significant correlation between kindlin-2 and interleukin expression, with the exception of IL10 and IL18 $(\mathrm{N}=6)$ (Table II). IL22 expression was significantly higher the in Hs-746T cell line than in the other two cell lines. IL18 and IL10 expressions were significantly lower in the metastatic cell lines compared to AGS (Table III).

Invasion rate of $\mathrm{Hs}-746 \mathrm{~T}$ cells in Matrigel after downregulation of kindlin-2. The cell invasion rates in Matrigel decreased significantly following downregulation of

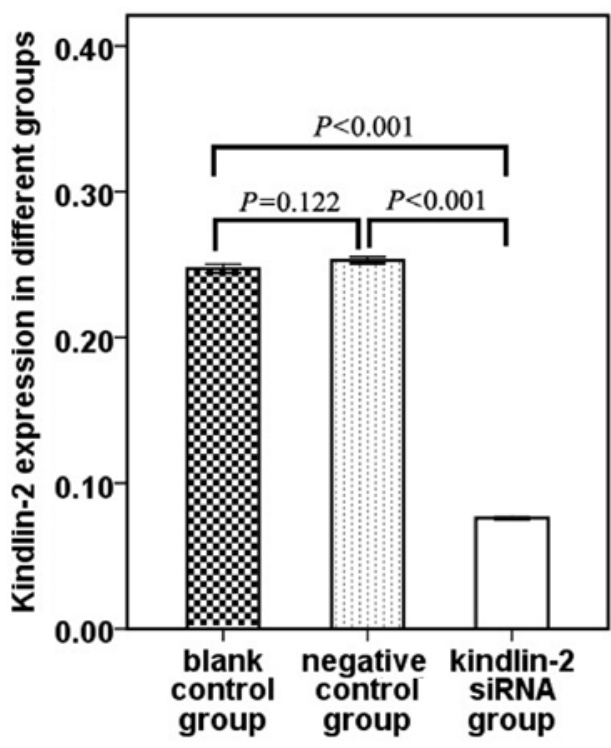

Figure 3. Kindlin-2 expression was downregulated in the kindlin-2 siRNA group compared to the other groups. There was no difference in kindlin-2 expression between the blank control and the negative control group.

kindlin-2 $(3.2 \pm 0.1 \mu \mathrm{m} / \mathrm{h})$ compared to the blank control group $(3.9 \pm 0.3 \mu \mathrm{m} / \mathrm{h}, \mathrm{P}<0.001)$ and the negative control group $(4.0 \pm 0.1 \mu \mathrm{m} / \mathrm{h}, \mathrm{P}<0.001, \mathrm{~N}=3)$.

Expression of interleukin in the Hs-746 cell line following downregulation of kindlin-2. As kindlin-2 relative expression was the highest in the Hs-746T cell line, we chose to downregulate kindlin-2 expression in this cell line. Real-time RT-PCR was used to verify the effect of kindlin-2 siRNA. We found that the level of mRNA expression in the kindlin-2 siRNA group (7.6 \pm 0.1$)$ was significantly lower than in the negative control group (25.3 \pm 0.2$)$ or in the blank control group $(24.7 \pm 0.1)$, and there was no significant difference between the negative control and the blank control group ( $\mathrm{N}=6$ ) (Fig. 3).

IL8 and IL18 expressions were significantly elevated following downregulation of kindlin-2 expression in the Hs-746T cell line compared to the blank control group. IL10, IL11, IL17b, IL22 and IL24 expressions were significantly decreased after downregulation of kindlin-2 expression $(\mathrm{N}=6)$ (Table IV).

Correlation between interleukin expression and invasion rate in Matrigel following downregulation of kindlin-2. There was 

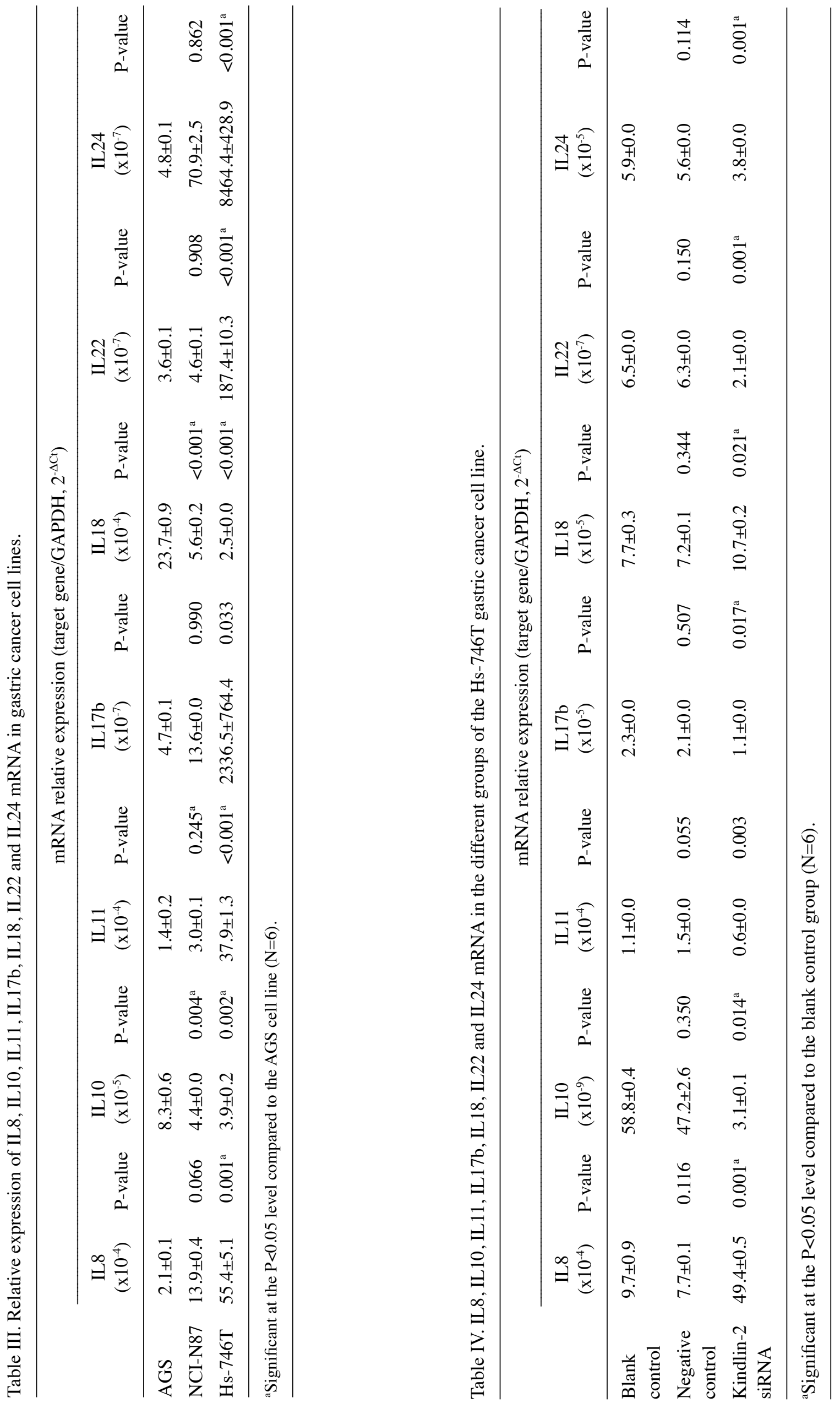
a significantly negative correlation between IL8, IL18 expression and gastric cancer cell migration rate in the Hs-746T cell line following downregualtion of kindlin-2 expression. $(\mathrm{r}=-0.987, \mathrm{P}<0.001 ; \mathrm{r}=-0.983, \mathrm{P}<0.001)$. There was a significantly positive correlation between IL10, IL11, IL17b, IL22 and IL24 expression and cell migration rate $(\mathrm{r}=0.842, \mathrm{P}=0.036$; $\mathrm{r}=0.922, \mathrm{P}<0.001 ; \mathrm{r}=0.920, \mathrm{P}=0.009 ; \mathrm{r}=0.974, \mathrm{P}=0.001)$.

\section{Discussion}

In recent years, studies of kindlin-2 as an important regulator of integrin activation have focused on the transformation and progression of tumors. In our two previous studies, we found that both kindlin-2 expression and chronic inflammation mediated by macrophages had an effect on the invasion of gastric cancer. However, little is known about the relationship between kindlin-2 expression and chronic inflammation. In this study, we found that kindlin-2 expression was upregulated by macrophages in all three gastric cancer cell lines. We speculated that kindlin-2 is involved in the process of tumor-associated inflammation, and tumor-associated macrophages (TAMs) could increase the invasion of cancer cells by enhancing the adhesion between cancer cells and extra-cellular matrix dependent on kindlin-2 upregulation.

The presence of multiple areas of hypoxia is a hallmark of cancer. A number of recent studies have shown that macrophages respond to the level of hypoxia in tumors by upregulating such transcription factors as hypoxia-inducible factors 1 and 2, which in turn activate a broad array of mitogenic, proinvasive, proangiogenic, and prometastatic genes (23). However, so far there have been no reports about the relationship between kindlin-2 expression, hypoxia and macrophages. In our study, we found that the response of kindlin-2 expression to the hypoxia with macrophages depended on the gastric cancer cell lines and it was downregulated most severely in the metastatic cell line.

Significant results have demonstrated that inflammation cytokines, especially interleukin, play an important role in chronic inflammation and cancer progression (24). Although kindlin-2 expression was found to be induced by TAMs in our study, we did not know the relationship between kindlin-2 and interleukins in the cancer cells. IL8 expression has been found in various human types of cancer including gastric cancer (25). It has been implicated in a variety of cellular processes, especially in angiogenesis through stimulation of endothelial cell migration and suppression of programmed cell death (26). In our study, IL8 was significantly elevated following downregulation of kindlin-2 expression with invasion rate in Matrigel decreased, suggesting that kindlin-2 might inhibit gastric cancer cell invasion through elevated IL8 expression. However, IL8 expression was high in the cell line with high kindlin-2 expression, which might be due to other signal pathways involved in the regulation of IL8 expression.

Data concerning the level of IL10 in gastric cancer patients display discrepancy. A study performed on 68 patients showed no correlation between serum IL10 level and the clinical course of disease (27). On the other hand, Szaflarska et al (28) reported that IL10 was elevated mostly in advanced disease and the increased levels were associated with significantly poorer survival of patients. Based on our results, we speculate that IL10 expression might depend on the type of gastric cancer and although its expression is low in the metastatic cell line with high kindlin-2 expression, downregulation of kindlin-2 might decrease the invasion of gastric cells through decreasing further IL10 expression.

IL11 was initially cloned as a mediator of plasmacytoma cell proliferation (29) and was later found to exhibit a wide variety of biological effects in neural cells as well as in the hematopoietic and the immune systems (30). It has previously been shown that expression of IL11 and its co-receptor were required for signal transduction and correlates with invasion and proliferation in gastric, and colorectal cancer $(20,31)$. We found that IL11 expression was not only high in the gastric cancer cell line with high kindlin-2 expression, but was also significantly decreased after inferring kindlin-2 mRNA expression and was positively correlated with invasion rate in Matrigel, suggesting a positive role of kindlin-2 signaling in IL11 expression for regulating gastric cancer cell invasion.

IL18 has been shown to have potent antitumor effects that are mediated by the induction of apoptosis and inhibition of angiogenesis $(32,33)$. However, some reports suggest that tumors could counterattack the immune system by secreting IL18 (34). The serum IL18 concentration was reported to be higher in metastatic cancer patients than in early cancer patients (35). We found that IL18 was not only weakly expressed in the metastatic cell line with high kindlin-2 expression, but its expression was also significantly increased after downregulation of kindlin-2. Therefore, kindlin-2 might contribute to the invasion of cancer cells through downregulation of IL18 expression, when macrophages interact with gastric cancer cells.

There are no previous reports on IL17b, IL22 and IL24 expression in gastric cancer. In this study, we found that these genes were expressed in three gastric cancer cell lines. Their expression correlated with kindlin-2 expression levels suggesting a role in promoting the invasion of gastric cancer cells. Moreover, downregulation of kindlin-2 expression induced a decrease in expression of these three interleukins. Therefore, kindlin-2 might be involved in the interaction between chronic inflammation and gastric cancer through positive regulation of 17b, IL22 and IL24 expression.

In conclusion, the novel adhesion gene kindlin-2 might play a role in promoting the invasion and metastasis of gastric cancer cells by TAMs and through regulating the expression of interleukins, such as IL8, IL10, IL11, IL17b, IL22 and IL24.

\section{Acknowledgements}

This study was supported by grants from the Sigrid Juselius Foundation and the Helsinki University Central Hospital Research Funds.

\section{References}

1. Rogalski TM, Mullen GP, Gilbert MM, Williams BD and Moerman DG: The UNC-112 gene in Caenorhabditis elegans encodes a novel component of cell-matrix adhesion structures required for integrin localization in the muscle cell membrane. J Cell Biol 150: 253-264, 2000.

2. Wegener KL, Partridge AW, Han J, et al: Structural basis of integrin activation by talin. Cell 128: 171-182, 2007. 
3. Ussar S, Wang HV, Linder S, Fässler R and Moser M: The Kindlins: subcellular localization and expression during murine development. Exp Cell Res 312: 42-51, 2006.

4. Shi X, Ma YQ, Tu Y, et al: The MIG-2/integrin interaction strengthens cell-matrix adhesion and modulates cell motility. J Biol Chem 282: 20455-20466, 2007.

5. Kim M, Carman CV and Springer TA: Bidirectional transmembrane signaling by cytoplasmic domain separation in integrins. Science 301: 1720-1725, 2003.

6. Montanez E, Ussar S, Schifferer M, Bösl M, Zent R, Moser M and Fässler R: Kindlin-2 controls bidirectional signaling of integrins. Genes Dev 22: 1325-1330, 2008.

7. An Z, Dobra K, Lock JG, Strömblad S, Hjerpe A and Zhang H: Kindlin-2 is expressed in malignant mesothelioma and is required for tumor cell adhesion and migration. Int J Cancer 127: 1999-2008, 2010.

8. Gong X, An Z, Wang Y, et al: Kindlin-2 controls sensitivity of prostate cancer cells to cisplatin-induced cell death. Cancer Lett 299: 54-62, 2010.

9. Kato K, Shiozawa T, Mitsushita J, et al: Expression of the mitogen-inducible gene-2 (mig-2) is elevated in human uterine leiomyomas but not in leiomyosarcomas. Hum Pathol 35: 55-60, 2004.

10. Sgambato A and Cittadini A: Inflammation and cancer: a multifaceted link. Eur Rev Med Pharmacol Sci 14: 263-268, 2010.

11. Hagemann T, Balkwill $F$ and Lawrence T: Inflammation and cancer: a double-edged sword. Cancer Cell 12: 300-301, 2007.

12. Mukhtar RA, Nseyo O, Campbell MJ and Esserman LJ: Tumorassociated macrophages in breast cancer as potential biomarkers for new treatments and diagnostics. Expert Rev Mol Diagn 11: 91-100, 2011.

13. Zhang BC, Gao J, Wang J, Rao ZG, Wang BC and Gao JF Tumor-associated macrophages infiltration is associated with peritumoral lymphangiogenesis and poor prognosis in lung adenocarcinoma. Med Oncol 28: 1447-1452, 2011.

14. Ohno S, Ohno Y, Suzuki N, et al: Correlation of histological localization of tumor-associated macrophages with clinicopathological features in endometrial cancer. Anticancer Res 24 3335-3342, 2004.

15. Hanada T, Nakagawa M, Emoto A, Nomura T, Nasu N and Nomura Y: Prognostic value of tumor-associated macrophage count in human bladder cancer. Int J Urol 7: 263-269, 2000

16. Leek RD, Lewis CE, Whitehouse R, Greenall M, Clarke J and Harris AL: Association of macrophage infiltration with angiogenesis and prognosis in invasive breast carcinoma. Cancer Res 56: 4625-4629, 1996.

17. Fujimoto H, Sangai T, Ishii G, et al: Stromal MCP-1 in mammary tumors induces tumor-associated macrophage infiltration and contributes to tumor progression. Int J Cancer 125: 1276-1284, 2009.

18. Koga F, Kageyama Y, Kawakami S, et al: Prognostic significance of endothelial Per-Arnt-sim domain protein 1/hypoxia-inducible factor-2alpha expression in a subset of tumor associated macrophages in invasive bladder cancer. J Urol 171: 1080-1084, 2004

19. Rajkumar T, Vijayalakshmi N, Gopal G, Sabitha K, Shirley S, Raja UM and Ramakrishnan SA: Identification and validation of genes involved in gastric tumorigenesis. Cancer Cell Int 10 : 45,2010 .
20. Jackson CB, Judd LM, Menheniott TR, et al: Augmented gp130mediated cytokine signalling accompanies human gastric cancer progression. J Pathol 213: 140-151, 2007.

21. Won HH, Kim JW, Kim MJ, Kim S, Park JH and Lee KA: Interleukin 10 polymorphisms differentially influence the risk of gastric cancer in East Asians and Caucasians. Cytokine 51: 73-77, 2010.

22. Mantovani A, Sozzani S, Locati M, Allavena P and Sica A: Macrophage polarization: tumor-associated macrophages as a paradigm for polarized M2 mononuclear phagocytes. Trends Immunol 23: 549-555, 2002.

23. Lewis C and Murdoch C: Macrophage responses to hypoxia: implications for tumor progression and anti-cancer therapies. Am J Pathol 167: 627-635, 2005.

24. Culig Z: Cytokine disbalance in common human cancers. Biochim Biophys Acta 1813: 308-314, 2011.

25. Savage SA, Abnet CC, Mark SD, et al: Variants of the IL8 and IL8RB genes and risk for gastric cardia adenocarcinoma and esophageal squamous cell carcinoma. Cancer Epidemiol Biomarkers Prev 13: 2251-2257, 2004.

26. Waugh D and Wilson C: The interleukin-8 pathway in cancer, Clin Cancer Res 14: 6735-6741, 2008.

27. Thong-Ngam D, Tangkijvanich P, Lerknimitr R, Mahachai V, Theamboonelrs A and Poovorawan Y: Diagnostic role of serum interleukin-18 in gastric cancer patients. World J Gastroenterol 12: 4473-4477, 2006.

28. Szaflarska A, Szczepanik A, Siedlar M, Czupryna A, Sierzega M, Popiela T and Zembala M: Preoperative plasma level of IL-10 but not of proinflammatory cytokines is an independent prognostic factor in patients with gastric cancer. Anticancer Res 29 . 5005-5012, 2009.

29. Paul SR, Bennett F, Calvetti JA, et al: Molecular cloning of a cDNA encoding interleukin 11, a stromal cell-derived lymphopoietic and hematopoietic cytokine. Proc Natl Acad Sci USA 87: 7512-7516, 1990

30. Du X and Williams DA: Interleukin-11: review of molecular, cell biology, and clinical use. Blood 89: 3897-3908, 1997.

31. Nakayama T, Yoshizaki A, Izumida S, et al: Expression of interleukin-11 (IL-11) and IL-11 receptor alpha in human gastric carcinoma and IL-11 upregulates the invasive activity of human gastric carcinoma cells. Int J Oncol 30: 825-833, 2007.

32. Okano F and Yamada K: Canine interleukin-18 induces apoptosis and enhances Fas ligand mRNA expression in a canine carcinoma cell line. Anticancer Res 20: 3411-3415, 2000.

33. Coughlin CM, Salhany KE, Wysocka M, et al: Interleukin-12 and interleukin-18 synergistically induce murine tumor regression which involves inhibition of angiogenesis. J Clin Invest 101: 1441-1452, 1998.

34. Cho D, Song H, Kim YM, et al: Endogenous interleukin-18 modulates immune escape of murine melanoma cells by regulating the expression of Fas ligand and reactive oxygen intermediates. Cancer Res 60: 2703-2709, 2000.

35. Lissoni P, Brivio F, Rovelli F, et al: Serum concentrations of interleukin-18 in early and advanced cancer patients: enhancedsecretion in metastatic disease. J Biol Regul Homeost Agents 14: 275-277, 2000. 